\title{
Wood capillarity and deacetylation during eucalyptus alkaline impregnation. Sulphidity effects and comparison between transverse directions
}

\author{
María Cristina Inalbon, Pablo N. Montagna, \\ María Verónica Galván, Luciano Demonte \\ and Miguel A. Zanuttini* \\ Instituto de Tecnología Celulósica, Facultad de Ingeniería \\ Química, Universidad Nacional del Litoral, Santiago del \\ Estero 2654, Santa Fe, Argentina \\ *Corresponding author. \\ Instituto de Tecnología Celulósica, Facultad de Ingeniería \\ Química, Universidad Nacional del Litoral, Santiago del Estero \\ 2654, Santa Fe, Argentina \\ E-mail: mzanutti@fiq.unl.edu.ar
}

\begin{abstract}
The relative ion transport capacity of wood - the "effective capillary cross sectional area" (ECCSA) - is determined in this work, based on the analogy with the relation between the electrical conductivities of wood and liquid medium. Wood was treated under different conditions and then the corresponding $\mathrm{ECCSA}_{\mathrm{A}}$ (the index $\mathrm{A}$ is for alkali) is estimated from the value obtained in an inert solution at room temperature $\left(\mathrm{ECCSA}_{\text {Inert }}\right)$. The difference between radial and tangential $\mathrm{ECCSA}_{\mathrm{A}}$ values is constant irrespective of $\mathrm{pH}$, time, temperature and the presence of sodium sulfide in the treatment liquor. The results show that $\mathrm{ECCSA}_{\mathrm{A}}$ is dependent on the degree of removal of native acetyl groups from hardwood O-acetyl-glucuronoxylan. A kinetic expression for Eucalyptus wood deacetylation is validated and used to establish the relationship between the acetyl content and $\mathrm{ECCSA}_{\mathrm{A}}$ in both anatomical directions
\end{abstract}

Keywords: alkaline pre-extraction; deacetylation kinetics; diffusion; effective capillarity.

\section{Introduction}

The extent of impregnation of wood chips is critical for the success of pulping processes. A higher degree of impregnation during kraft pulping leads to a more homogeneous pulp, which is indicated by a narrow distribution of the kappa number of the individual fibers (Malkov et al. 2003). Incomplete impregnation affects the yield, strength, and bleachability of pulp and elevates the amount of uncooked rejects (Gullichsen et al. 1992, 1995; Malkov et al. 2002).

Improvement of impregnation under controlled conditions could have many benefits. Within the scope of a forest biorefinery concept, alkaline pre-extraction in a kraft pulp mill permits the separation of a part of the hemicelluloses, which can be considered as an additional value-added product. Biorefinery is an emerging research field, with its multifunctional challenges as demonstrated by a large body of recent publications, for example: Dautzenberg et al. (2011), Schütt et al. (2011), López et al. (2011), Kirsch et al. (2011), Hörhammer et al. (2011), Gütsch and Sixta (2011), Testova et al. (2011), just to mention a few. Al-Dajani and Tschirner (2008) showed that 40 to $50 \mathrm{~kg}$ xylan $\mathrm{t}^{-1}$ of poplar wood can be separated by preextraction and the alkali consumption of the subsequent kraft pulping is reduced. The situation is even more favorable in sulfur-free processes. In a soda-anthraquinone eucalyptus pulping, for example, xylan can be obtained in polymeric form with very low lignin contamination by ultrafiltration and subsequent precipitation (Schild et al. 2010; Sixta et al. 2011).

A deeper understanding of alkaline impregnation and preextraction of wood may be useful for a detailed modeling and optimization. For that, two different aspects must be known: (a) the effective diffusion coefficient for the relevant chemical species and (b) a kinetic expression of involved reactions.

The hemicellulose component of eucalyptus wood is acetylated, as many hemicelluloses of different plant tissues are. The removal of native acetyl groups from hardwood O-acetylglucuronoxylan or softwood O-acetyl-galactoglucomannans can have a major effect on both the physical characteristics of the polymer and the structure of the cell wall. For instance, the cell wall accessibility is particularly increased in softwoods (Sjöström and Häglund 1961) but also in hardwoods (Sumi et al. 1964).

Deacetylation is the main reaction that takes place during the first stage of any alkaline pulping process. For hardwoods, it is responsible for a considerable part of the alkali consumption (Zanuttini et al. 2003). The alkaline impregnation process is complex. Instead of following an unsteady-state Fickean diffusion, a reaction front is established and moves to the interior of wood. Hence, an intact inner zone can be differentiated from a reacted swollen outer zone (Zanuttini et al. 2003).

The wood properties change significantly in each position of the chips due to the alkali action during impregnation. Nevertheless, there is little information available regarding the dynamic dependence of the effective diffusion coefficient on alkalinity, temperature, the presence of sulfide and the anatomical wood directions.

The relative ion transport capacity of wood, which is related to the "effective capillary cross-sectional area" (ECCSA), has been determined based on the analogy with the relation between electrical conductivities of the wood and the liquid medium (Stone and Green 1958). The ECCSA concept allows expressing the effective diffusion coefficient $\left(D_{\text {effective }}^{i}\right)$ as: 
$D_{\text {effective }}^{i}=D^{i * E C C S A}$

where $D^{i}$ is the diffusion coefficient of the " $i$ " ionic species in the liquid medium.

The dependence of ECCSA on alkali concentration has been analyzed at room temperature for the three anatomical directions of aspen wood (Stone and Green 1958). In a previous work, an enhanced method was described which allows following the evolution of ECCSA of wood while it is under the action of an alkaline treatment. For eucalyptus wood, ECCSA dependence on alkalinity, temperature and chemical reaction degree has been experimentally determined (Inalbon and Zanuttini 2008).

In the present work, the analysis is further extended. A correlation was found between the ECCSA of wood under the action of hot kraft liquor $\left(\mathrm{ECCSA}_{\mathrm{A}}\right)$ and the ECCSA in $\mathrm{NaCl} 0.1 \mathrm{~N}$ at $20^{\circ} \mathrm{C}\left(\mathrm{ECCSA}_{\text {Inert }}\right)$. Based on this correlation, more reliable results can be obtained by faster determination in a large number of samples. Variations in ECCSA $_{\mathrm{A}}$ and the influence of variables will be determined for both transverse directions of eucalyptus wood. Finally, based on deacetylation kinetics, a relation will be established between the reaction degree and the $\mathrm{ECCSA}_{\mathrm{A}}$, which can be useful for a detailed description and modeling of the impregnation.

\section{Materials and methods}

\section{Preparation of wood slices}

Green, fresh wood (Eucalyptus grandis) with sapwood with an average basic density of $0.366 \mathrm{~kg} \mathrm{l}^{-1}$ was investigated. Logs from 6-yearold trees were supplied by INTA, Concordia, Argentina. Logs were sawn into disks of approximately $3.5 \mathrm{~cm}$ thickness and then stored in polyethylene bags at $-10^{\circ} \mathrm{C}$. From the sapwood of disks, cubes with $35 \mathrm{~mm}$ side lengths were sawn. The faces of the cubes corresponded to tangential, transverse and approximately radial cuts. Slices (350 $\mu \mathrm{m}$ thickness) were obtained from radial and tangential faces of the cubes by a microtome. The slices were impregnated with distilled water by means of vacuum impregnation (6 cycles of $720 \mathrm{~mm} \mathrm{Hg}$ vacuum and release).

\section{Effective capillarity determination}

For the determination of the ECCSA, a laboratory conductivity cell and an especially designed frame were used (Inalbon and Zanuttini 2008). In the procedure, the wood slice is mounted to the frame to keep it flat and equidistant from the electrodes. Both faces of the slice are in contact with the solution. The dynamic specific conductivity of the wood is calculated considering slice thickness and electrical resistance in a series circuit with the electrical resistance of the solution existing between electrodes. Wood slices cut in a radial direction allowed the determination of the specific conductivity in the tangential direction and vice versa.

\section{Determination of ECCSA $A_{A}$ and $E_{C C S A} A_{\text {Inert }}$}

ECCSA of wood under the action of alkali $\left(\mathrm{ECCSA}_{\mathrm{A}}\right)$ or alkaline sulfide treatment was determined under different conditions (Table 1). The solution concentration during the experiments can be considered as constant due to the high liquor to wood ratio (1000 g solution
Table 1 Treatment conditions for ECCSA Inert $_{\text {and }}$ ECCSA

\begin{tabular}{|c|c|c|c|c|}
\hline \multirow{2}{*}{$\begin{array}{l}\text { Solution for } \\
\text { ECCSA }_{\text {Inert }} \\
\text { or } \text { ECCSA }_{A}\end{array}$} & \multirow[b]{2}{*}{ Direction } & \multicolumn{3}{|c|}{ Treatment time (min) } \\
\hline & & $20^{\circ} \mathrm{C}$ & $45^{\circ} \mathrm{C}$ & $90^{\circ} \mathrm{C}$ \\
\hline $0.1 \mathrm{M} \mathrm{NaOH}$ & Tangential & $5-30$ & $5-10-15-20-25$ & $5-15$ \\
\hline $0.1 \mathrm{M} \mathrm{NaOH}$ & Radial & & $5-15-25$ & \\
\hline $0.1 \mathrm{M} \mathrm{Na}_{2} \mathrm{~S}$ & Tangential & & $5-20$ & \\
\hline
\end{tabular}

to $0.2 \mathrm{~g}$ wood). The conductivity was continuously registered during the treatment. Once treatment was finished, the slices were immediately immersed in distilled water to stop the reaction. After washing, they were immersed in $0.1 \mathrm{~N} \mathrm{NaCl}$ solution for at least $8 \mathrm{~h}$. Finally, the ECCSA was determined at $20^{\circ} \mathrm{C}$ in the same solution concentration. This parameter was called ECCSA Inert $_{\text {, which is stable over }}$ time, because no reaction takes place. Measurements were done on six slices under each condition. Tangential and radial directions were considered.

\section{Effects of variables on ECCSA}

Slices were placed into a basket of stainless steel mesh with internal compartments. The basket allows the slices and solution to be in contact, and at the same time maintains slices separated from each other. Baskets with slices were placed in a thermostated solution, the concentration of which can be regarded as constant during the treatment due to the high liquor to wood ratio (1000 g solution to $2 \mathrm{~g}$ wood). As the treatment time was reached, baskets were transferred to cold distilled water and washed. Then, slices were immersed in $0.1 \mathrm{~N} \mathrm{NaCl}$ solution for at least $8 \mathrm{~h}$. Finally, the $\mathrm{ECCSA}_{\text {Inert }}$ was determined in this solution.

Treatment conditions are presented in Table 2. Each treatment was done on five slices. The ECCSA of each slice was calculated based on the corresponding ECCSA $_{\text {Inert }}$.

\section{Acetyl group determination}

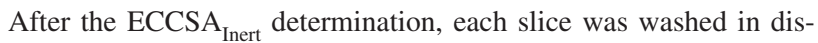
tilled water and air dried. The acetyl content of the slices was analyzed by diffuse reflectance FTIR (DRIFT) based on the relationship between band height at $1735 \mathrm{~cm}^{-1}$ and the acetyl content determined by GC (Zanuttini et al. 1998). The acetyl band at $1735 \mathrm{~cm}^{-1}$ was normalized to the $1510 \mathrm{~cm}^{-1}$ band (aromatic ring of lignin).

The acetyl content of wood slices was determined by GC according to Solár et al. (1997). Butyric acid instead of propionic acid was used as the internal standard. Samples (100-150 mg) were treated at $150^{\circ} \mathrm{C}$ for $50 \mathrm{~min}$ in closed glass ampoules with $1.25 \mathrm{ml}$ of a liquor containing oxalic acid (63 $\mathrm{g}$ oxalic acid dihydrate $\left.\mathrm{l}^{-1}\right)$, and butyric

Table 2 Variables considered for the experimental analysis of ECCSA $_{\mathrm{A}}$.

\begin{tabular}{ccccc}
\hline $\begin{array}{c}\text { Temperature } \\
\left({ }^{\circ} \mathrm{C}\right)\end{array}$ & Time (min) & $\mathrm{pH}$ & $\begin{array}{c}\text { Sullphidity } \\
(\%)\end{array}$ & Direction \\
\hline $20-45-90$ & $5-10-20-40$ & $12-13-14$ & $0-25$ & $\begin{array}{c}\text { Tangential } \\
- \text { Radial }\end{array}$ \\
\hline
\end{tabular}

Sulphidity (\%): $100 \cdot\left[\mathrm{Na}_{2} \mathrm{~S} /\left(\mathrm{NaOH}+\mathrm{Na}_{2} \mathrm{~S}\right)\right]$, where $\mathrm{Na}_{2} \mathrm{~S}$ and $\mathrm{NaOH}$ is expressed as $\mathrm{NaOH}$. 
acid $\left(1.8 \mathrm{ml} \mathrm{l}^{-1}\right)$. Acetyl content is reported as the weight $\% \mathrm{CH}_{3} \mathrm{CO}$ based on oven-dry (o.d.) wood.

\section{Results and discussion}

\section{ECCSA estimation from the ECCSA Inert $_{\text {In }}$}

Figure 1 shows the ECCSA $_{\mathrm{A}}$ directly determined at the end of the alkaline or alkaline sulfide treatments under the conditions presented in Table 1 and the corresponding ECCSAvalues obtained afterwards in $\mathrm{NaCl}$ at $20^{\circ} \mathrm{C}$ (ECCSA Inert ).

The relatively high scattering of ECCSA-values around each average can be ascribed, in a great part, to wood heterogeneity. The standard deviation is increased as the average ECCSA-values are increased. In most cases, dispersion is lower for $\mathrm{ECCSA}_{\text {Inert }}$. As visible, a linear relationship can be established irrespectively of treatment conditions. The correlation equation is presented in the plot.

The alkali increases the material transport capacity of wood. The main part of this effect remains when alkali is removed, so it can be attributed to the removal of the acetyl and reaction of the acid groups, which opens pathways to the ions passage. The smaller part of the effect disappears when the alkali is removed. This part is due to the alkaline swelling. This effect is independent of the alkali concentration in the treatment.

The relationship permits a relevant simplification for the determination of ECCSA $_{A}$, because it allows treating a set of slices simultaneously, and then the individual ECCSA $_{\mathrm{A}}$ of each slice can be calculated from the corresponding $\mathrm{ECCSA}_{\text {Inert }} \mathrm{ECCSA}_{\mathrm{A}}$ for each condition arises from the average. This method is faster and more reliable. Thus more

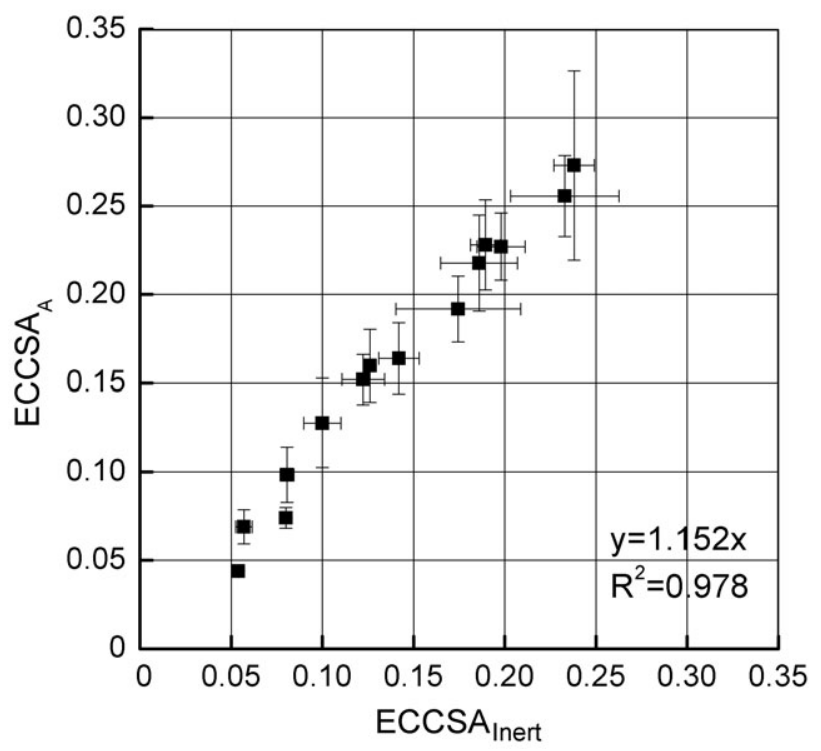

Figure 1 Effective capillarity $\left(\mathrm{ECCSA}_{\mathrm{A}}\right)$ of wood determined under alkaline treatment vs. the corresponding data of ECCSA $_{\text {Inert }}$. Points are the average for each treatment conditions and bars indicate standard deviations. data can be obtained, which compensates the effect of wood heterogeneity. ECCSA $\mathrm{A}_{\mathrm{A}}$ values discussed in this paper were determined with this procedure.

\section{ECCSA evolution during alkaline treatment}

Slices were treated in $\mathrm{Na}_{2} \mathrm{~S}$ and/or $\mathrm{NaOH}$ solution under different conditions (Table 2). Figure 2 shows ECCSA obtained for treatment at $25 \%$ sulphidity. ECCSA $\mathrm{A}_{\mathrm{A}}$ is gradually increased as a function of time. A favorable effect of $\mathrm{pH}$ is also clear. In fact, the level reached after $40 \mathrm{~min}$ is higher if wood is treated with a $\mathrm{pH} 14$ solution. On the other hand, data in the radial direction are always higher than in

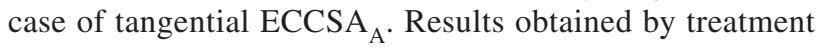
without sodium sulfide were similar (data not shown in the figure).

\section{Comparison between transverse ECCSA $_{A}$ values}

Figure $3 \mathrm{a}$ shows the plot radial ECCSA $\mathrm{A}$ vs. the tangential $\mathrm{ECCSA}_{\mathrm{A}}$. Expectedly, the former is always higher than the latter, due to the contribution of ray cells to the radial diffusion. Ray cells of the wood under study are shown in a SEM photograph in Figure 4. These results are in agreement with those obtained by Stone and Green (1958) for aspen wood (data shown in Figure $3 \mathrm{a}$ as triangles). The quoted authors used a different device and obtained the ECCSA at different $\mathrm{pH}$ levels after $24 \mathrm{~h}$ treatment at room temperature. Our results show that the difference between radial and tangential ECCSA (0.06 units) is independent of pH, time, temperature and the presence of sodium sulfide. As the SEM micrograph reveals, the free sectional area represented by the ray cells amounts to $5.9 \%$ of the total area. This could justify the 0.06 units higher radial ECCSA compared to the tangential one.

\section{Effect of sodium sulfide}

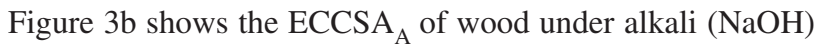

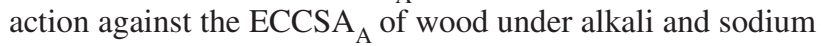
sulfide $\left(\mathrm{Na}_{2} \mathrm{~S}+\mathrm{NaOH}\right)$ action at the same alkalinity level. No significant effects are visible concerning the presence of sodium sulfide. These results are, in a great part, in agreement with literature data. Törnqvist et al. (2004) studied the effects of the HS- ion in the diffusion at $\mathrm{pH} 14$ for pine, birch and spruce. The authors used a diffusion cell (a thin piece of wood in contact with two solutions of different concentrations), and demonstrated in their theoretical analysis only a minor influence of $\mathrm{HS}^{-}$on the so called "apparent porosity" of the wood.

\section{Relationship between ECCSA $A_{A}$ and reaction degree}

Deacetylation reaction The contents of acetyl groups after treatment under different conditions (Table 2) were determined and the kinetic expression for the deacetylation reaction rate $\left(\mathrm{R}_{\text {Acetyl }}, \% \mathrm{~min}^{-1}\right)$ previously published (Inalbon et al. 2009) was fitted to data. 

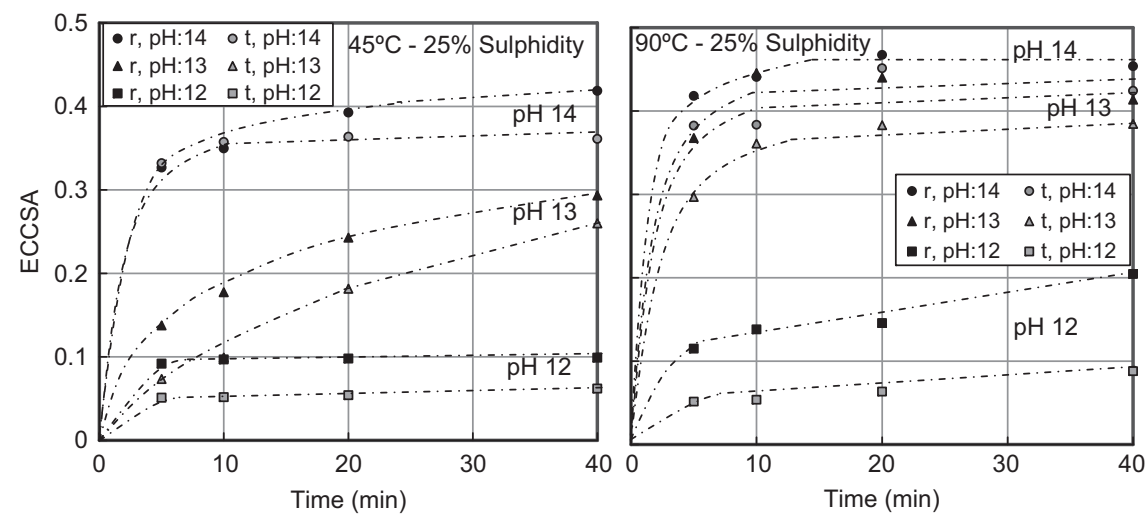

Figure 2 Evolution of $\mathrm{ECCSA}_{\mathrm{A}}$ for radial (r) and tangential ( $\mathrm{t}$ ) slices treated with kraft liquor (sulphidity $25 \%$ ).
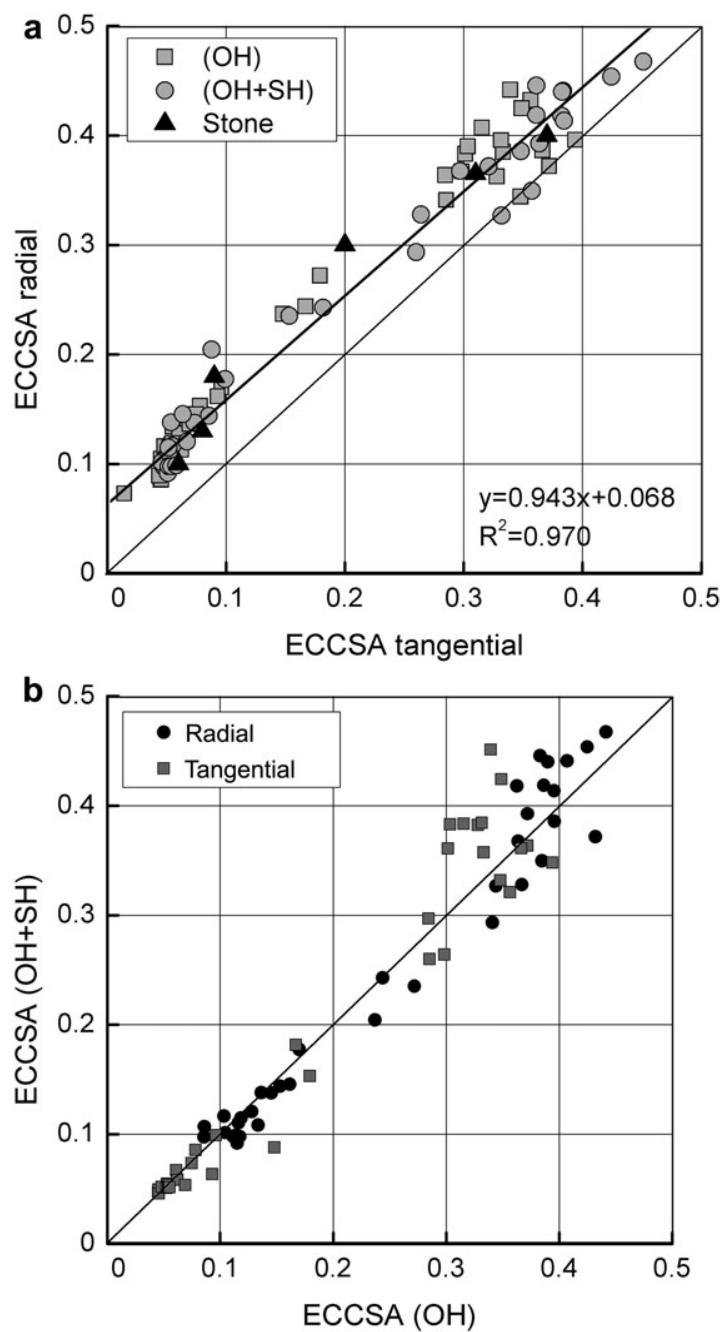

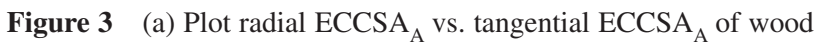
under the action of kraft liquor under the conditions presented in Table 2. Stone: Stone and Green (1958), see References and (b) plot ECCSA $_{\mathrm{A}}$ of wood treated with $\mathrm{NaOH}$ vs. ECCSA $\mathrm{A}$ of wood treated with $\mathrm{NaOH}$ and $\mathrm{Na}_{2} \mathrm{~S}$ at the same alkalinity. The conditions are listed in Table 2.

$$
\begin{aligned}
& R_{\text {Acetyl }}=\frac{-\partial C_{\text {Acetyl }}}{\partial t} \\
&=k \cdot\left(C_{\text {Acetyl }}\right)^{n} \cdot\left(C_{O H}\right)^{m} \cdot\left(C_{N a}\right)^{p} \\
& k=A \cdot \exp \left(\frac{-E}{R T}\right)
\end{aligned}
$$

where:

$k=$ the specific rate constant of deacetylation $\left[(\%)^{1-n(m+p)}\right.$ $\left.\mathrm{mo1}^{-(m+p)} \mathrm{min}^{-1}\right]$

$C_{\text {Acetyl }}=$ the acetyl concentration on o.d. $\operatorname{wood}(\%)$

$\mathrm{C}_{\mathrm{OH}}$ the alkali concentration $\left(\mathrm{mol} \mathrm{l}^{-1}\right)$

$C_{N a}=$ the sodium concentration $\left(\mathrm{mol} \mathrm{l}^{-1}\right)$

$R=$ the gas constant $\left(8.314 \mathrm{~J} \mathrm{~mol}^{-1} \mathrm{~K}^{-1}\right)$

$T=$ the absolute temperature $(\mathrm{K})$

$t=$ time (min)

$E=\operatorname{activation}$ energy $\left(\mathrm{J} \mathrm{mol}^{-1}\right)$

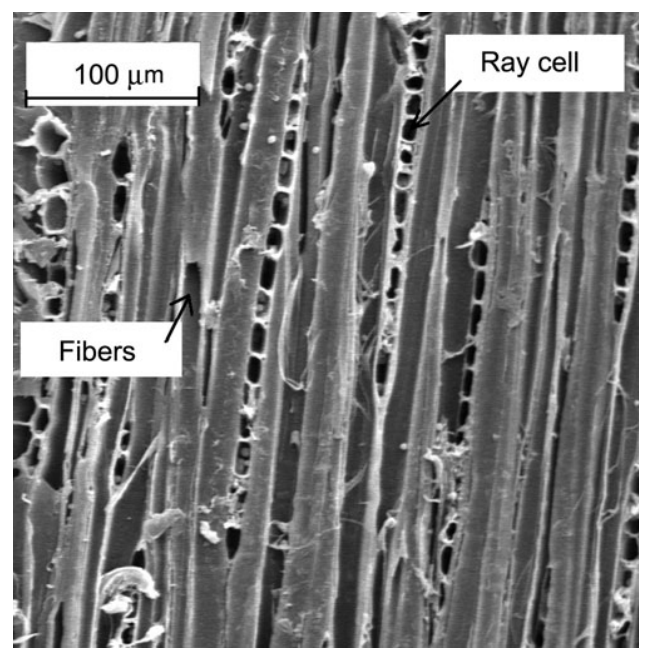

Figure 4 SEM photograph of a tangential section of Eucalyptus wood. 
$n=$ the acetyl reaction order

$m=$ the alkali reaction order

$p=$ the sodium reaction order

$A=$ the pre-exponential factor $\left[\left.(\%)^{1-n}\right|^{(m+p)} \operatorname{mol}^{-(m+p)} \min ^{-1}\right]$

The parameters obtained for the experiments made on radial and tangential slices are listed in Table 3 . The values are close to those published before for the same raw material (Inalbon et al. 2009), when only alkali was present in the treatment liquor.

Expectedly, the anatomical direction of the slice, which is a physical parameter, has no influence on the reaction rate, which is governed by chemical laws. Therefore, a single correlation for all data (radial and tangential ones) was used for the kinetic expression adopted here. In Eq. (2), hydrosulfide ion concentration seems to have no influence on kinetics. Nevertheless, its effect is taken into account by the sodium concentration, which is equal to the concentrations of added hydroxide and hydrosulfide ions.

Expression of ECCSA $A_{A}$ dependence on variables The dependence of the $\mathrm{ECCSA}_{\mathrm{A}}$ on temperature, time and $\mathrm{pH}$ is complex and difficult to mathematically express. Figure 5 shows tangential and radial ECCSA $_{\mathrm{A}}$ as a function of acetyl

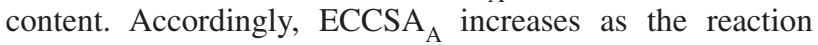
proceeds. The increase is notable when acetyl groups content is lower than $50 \%$ of the original in wood, and ECCSA reaches the highest level (similar for radial and tangential direction) when the reaction is completed. As ECCSA seems to have the same relation for any temperature and $\mathrm{pH}$, it can be considered that the acetyl group content is the determinant for the ECCSA $\mathrm{A}_{\mathrm{A}}$. This finding is in agreement with the previous results (Inalbon and Zanuttini 2008), for which, less variables were available.

Consequently, an expression for $\mathrm{ECCSA}_{\mathrm{A}}$ as a function of acetyl content can be obtained with an acceptable fitting for radial, as well as tangential, ionic diffusion.

$$
\begin{aligned}
& \begin{aligned}
\mathrm{ECCSA}_{\text {Radial }}= & 0.418-0.2881 \cdot \mathrm{C}_{\text {Acetyl }}+0.0899 \cdot \mathrm{C}_{\text {Acetyl }}^{2} \\
& -0.0094 \cdot \mathrm{C}_{\text {Acetyl }}^{3} \\
\mathrm{R}_{\text {adjusted }}^{2}=96.9 \% & \\
\text { ECCSA }_{\text {Tangential }} & =0.401-0.3325 \cdot \mathrm{C}_{\text {Acetyl }} \\
& +0.1034 \cdot \mathrm{C}_{\text {Acetyl }}^{2}-0.01056 \cdot \mathrm{C}_{\text {Acetyl }}^{3}
\end{aligned}
\end{aligned}
$$

Table 3 Fitted parameters for the kinetic expression. Experiences made on radial and tangential slices.

\begin{tabular}{lccc}
\hline Parameters & Tangential & Radial & $\begin{array}{c}\text { Independent } \\
\text { of anatomical } \\
\text { direction }\end{array}$ \\
\hline$C_{\text {Acetyl }}^{0}(\%)$ & 3.566 & 3.34 & 3.46 \\
$A$ & $9.779 \times 10^{6}$ & $9.779 \times 10^{6}$ & $9.779 \times 10^{6}$ \\
$E / R(\mathrm{~K})$ & -4893 & -4952 & -4918 \\
$n$ & 1.735 & 1.735 & 1.735 \\
$m$ & 1 & 1 & 1 \\
$p$ & 0.491 & 0.491 & 0.491 \\
$R_{\text {adjusted }}^{2}$ & 97.09 & 95.39 & 96.20 \\
\hline & & &
\end{tabular}

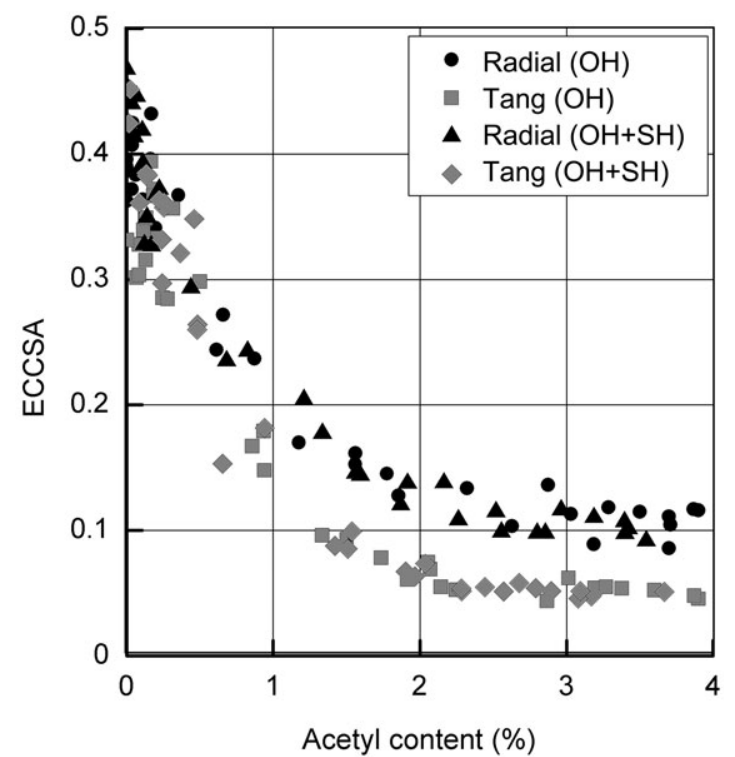

Figure 5 ECCSA $_{\mathrm{A}}$ as a function of acetyl content (\%), see Table 2.

$\mathrm{R}_{\text {adjusted }}^{2}=95.7 \%$.

For both radial and tangential directions, the expression includes the effects of all variables (temperature, time and $\mathrm{pH}$ ) using only one dependent variable (reaction degree), for which a kinetic expression is known. ECCSA $_{\mathrm{A}}$ as a function of acetyl content, together with the deacetylation kinetics, are specific for the wood species under consideration. However, they can be very useful for a differential mass balance in a rigorous modeling of the impregnation.

\section{Conclusions}

The relative ion transport capacity of wood under the action of alkaline and alkaline sulfide treatment $\left(\right.$ ECCSA $\left._{\mathrm{A}}\right)$ can be

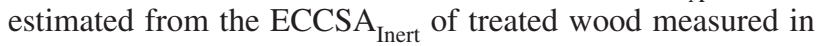
$\mathrm{NaCl}$ solution at room temperature. This approach allows more determinations to be obtained in less time and helps equalize scattering due to wood heterogeneity.

The increase in the material transport capacity can be ascribed to two contributions. The main one is the reactions of acetyls and acid groups. It remains when alkali is removed. The other contribution is lower and is related to the alkaline swelling. ECCSA $\mathrm{A}_{\mathrm{A}}$ evolution shows that the alkalinity level has a strong influence on the process, while the presence

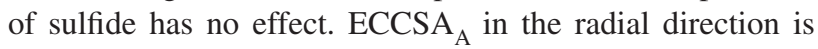
always higher compared to that in the tangential direction. The magnitude of the difference (0.06 units) is in close correlation to the free cross section in microscopic images, which are ascribable to the lumen of ray cells in wood.

The degree of alkaline deacetylation is determinant for the ECCSA $_{\mathrm{A}}$. The acetyl content has to be reduced to $<2.0 \%$, to increase the wood porosity useful for ion diffusion. Of course, the $\mathrm{ECCSA}_{\mathrm{A}}$ does not depend only on the acetyl content, but 
this assumption is a useful simplification of the mathematical representation of the impregnation with alkali. The nonlinear relationships found between ECCSA EC $_{\mathrm{A}}$ and the deacetylation degree of eucalyptus, is helpful for the theoretical analysis of the impregnation process.

\section{Acknowledgements}

Financial support from UNL, ANPCyT and CONICET is gratefully acknowledged. Thanks are also due to Martín Sánchez Acosta from INTA-Concordia for supplying the raw material. The authors also thank Miguel Citroni for assistance with IR determinations.

\section{References}

Al-Dajani, W.W., Tschirner, U.W. (2008) Pre-extraction of hemicelluloses and subsequent kraft pulping. Part I: alkaline extraction. Tappi J. 7:3-8.

Dautzenberg, G., Gerhardt, M., Kamm, B. (2011) Bio based fuels and fuel additives from lignocellulose feedstock via the production of levulinic acid and furfural. Holzforschung 65: $439-451$.

Gullichsen, J., Hyvärinen, R., Sundqvist, H. (1995) On the nonuniformity of the kraft cook Part 2. Paperi Ja Puu. 77: 331-337.

Gullichsen, J., Kolehmainen, H., Sundqvist, H. (1992) On the nonuniformity of the kraft cook. Paperi Ja Puu. 74:486-490.

Gütsch, J.S., Sixta, H. (2011) Purification of Eucalyptus globulus water prehydrolyzates using the HiTAC process (hightemperature adsorption on activated charcoal). Holzforschung 65:511-518.

Hörhammer, H., Walton, S., van Heiningen, A. (2011) A larch based biorefinery: pre-extraction and extract fermentation to lactic acid. Holzforschung 65:491-496.

Inalbon, M.C., Zanuttini, M.A. (2008) Dynamics of the effective capillary during the alkaline impregnation of eucalyptus wood. Holzforschung 62:397-401.

Inalbon, M.C., Mocchiutti, P., Zanuttini, M. (2009) The deacetylation reaction in eucalyptus wood. Kinetics and effects on the effective diffusion. Bioresour. Technol. 100:2254-2258.

Kirsch, C., Zetzl, C., Smirnova, I. (2011) Development of an integrated thermal and enzymatic hydrolysis for lignocellulosic biomass in fixed-bed reactors. Holzforschung 65:483-489.

López, Y., Gullón, B., Puls, J., Parajó, J.C., Martín, C. (2011) Dilute acid pretreatment of starch-containing rice hulls for ethanol production. Holzforschung 65:467-473.
Malkov, S., Tikka, P., Gullichsen, J. (2002) Towards complete impregnation of wood chips with aqueous solutions. Part 4. Effects of front-end modifications in displacement batch kraft pulping. Paperi Ja Puu. 84:526-530.

Malkov, S., Tikka, P., Gullichsen, R., Nuopponen, M., Vuorinen, T. (2003) Towards complete impregnation of wood chips with aqueous solutions. Part 5: Improving uniformity of kraft displacement batch pulping. Paperi ja Puu. 85:215-220.

Schild, G., Sixta, H., Testova, L. (2010) Multifunctional alkaline pulping, delignification and hemicellulose extraction. Cellul. Chem. Technol. 44:35-45.

Schütt, F., Puls, J., Saake, B. (2011) Optimization of steam pretreatment conditions for enzymatic hydrolysis of poplar wood. Holzforschung, 65:453-459.

Sixta, H., Guetsch, J., Nousiainen, T., Wollboldt, P. (2011) Progress and challenges in the isolation of xylan from Eucalyptus wood. $5^{\text {th }}$ International Colloquium on Eucalyptus Pulp, May 9-12, 2011, Porto Seguro, BA Brazil.

Sjöström, E., Häglund, P. (1961) Studies of factors affecting the determination of carboxyl groups in cellulose. Svensk Papperstidn. 64:438-446.

Solár, R., Kacik, F., Melcer, Y. (1997) Simple semimicro method for the determination of O-acetyl groups in wood and related materials. Nordic Pulp Paper Research J. 2:139-141.

Stone, J.E., Green, H.V. (1958) Penetration and Diffusion into Hardwoods. Pulp Paper Mag. Can. 58:223-232.

Sumi, Y., Hale, R.D., Meyer, J.A., Leopold, A.B., Ranby, B.G. (1964) Accessibility of wood and wood carbohydrates measured with tritiated water. Tappi J. 47:621-624.

Testova, L., Chong, S.-L., Tenkanen, M., Sixta, H. (2011) Autohydrolysis of birch wood. Holzforschung 65:535-542.

Törnqvist, M., Hurme, T., Rosenholm, J. B. (2004) The effect of $\mathrm{SH}^{-}$ ions in $1 \mathrm{~mol} / \mathrm{dm}^{3} \mathrm{NaOH}$ solutions on the ion diffusion in wood calculated by combining the drift speed and the steady state ion diffusion. Colloids and surfaces A: Physicochem. Eng. Aspects. 232:191-197.

Zanuttini, M., Citroni, M., Martinez, M.J. (1998). Application of diffuse reflectance infrared Fourier transform spectroscopy to the quantitative determination of acetyls groups in wood. Holzforschung 52:263-267.

Zanuttini, M., Marzocchi, V., Citroni, M., Mocchiutti, P. (2003) Alkali impregnation of hardwoods. Part I. Moderate treatment of poplar wood. J.P.P.S. 29:3131-3137.

Received February 24, 2012. Accepted July 30, 2012. Previously published online August 28, 2012. 